\section{Persisting arguments about visual persistence: Reply to Long}

\author{
DAVID E. IRWIN and JAMES M. YEOMANS \\ Michigan State University, East Lansing, Michigan
}

In a recent paper we investigated the effect of stimulus duration on partial report performance (Yeomans \& Irwin, 1985). Two experiments showed that variations in stimulus duration from 50 to $500 \mathrm{msec}$ had little or no effect on partial report accuracy, decay, or error patterns. Our results contrasted with previous research demonstrating that increasing stimulus duration decreases visible persistence duration (e.g., Bowen, Pola, \& Matin, 1974; Cohene, 1975; Di Lollo, 1977, 1980; Efron, 1970a, 1970b, 1970c; Haber \& Standing, 1970). We concluded that our findings provided support for the argument (Coltheart, 1980) that informational persistence (knowledge about the visual properties of a stimulus, as accessed by partial report) is a phenomenon that is separate from visible persistence (the phenomenal persistence of a stimulus), and we suggested that the traditional view of iconic memory, which conflates these two forms of persistence, is incorrect. We proposed, as a replacement to the traditional view, a two-stage model in which a brief period of visible persistence initiated at stimulus onset and sensitive to stimulus energy is followed by a longer period of informational persistence which begins at stimulus offset and is relatively insensitive to stimulus energy.

In a recent note, Long (1985a) took exception to the conclusions of our study. He made two specific criticisms-first, that it is dangerous to base a model on a null effect; and second, that we overlooked substantial empirical evidence that was inconsistent with the two-stage model we proposed. We address each of these criticisms below.

\section{The Null Effect}

Let us first consider Long's (1985a) criticism that "a null effect is a logically weak position on which to base a model-especially given a notoriously complex and 'noisy' experimental task' (p. 381). Long argues that the partial-report task is not a particularly easy one for subjects to perform, in part because it is not a "pure" measure of visual persistence. We certainly agree-in fact, one purpose of our study was to show that partial report is not a "pure" persistence measure. Because the partial-

\footnotetext{
Preparation of this manuscript was supported by a grant from the $\mathrm{Na}$ tional Science Foundation (Grant No. BNS-8519580) to David E. Irwin. We thank Kathryn Bock and Joseph Brown for their comments on an earlier version of the manuscript. Send requests for reprints to David E. Irwin, Department of Psychology, Michigan State University, East Lansing, MI 48824.
}

report task is difficult, Long argues that subjects often require substantial practice in order to produce stable data. To illustrate this point, Long reports that in one of his recent studies (Long \& Beaton, 1982), unpracticed subjects produced extremely noisy data and showed substantial individual differences. Long suggests that if we had given our subjects more practice, we might have obtained qualitatively different results.

Practice is surely a good thing. But our subjects' data were not particularly noisy. In Experiment 1, accuracy for all 6 subjects decreased (although not always monotonically) as cue delay increased for both $50-$ and $200-$ msec exposure durations. In Experiment 2, accuracy for all 6 subjects decreased as cue delay increased for 50 and 200-msec exposures, and for 5 of the 6 subjects for 500 -msec exposures. So we are quite comfortable with the quality of our data. We can think of two reasons why our data were more stable than Long and Beaton's (1982): First, accuracy in each condition of our experiments was based on 75 (Experiment 1) or 45 (Experiment 2) responses per subject, whereas in the Long and Beaton study, accuracy was based on only 16 responses per subject; and second, stimulus luminance was kept fairly constant in our experiment (except for relatively small variations due to differences in exposure duration), whereas in the Long and Beaton study, background and target luminances varied from .34 to $102.8 \mathrm{~cd} / \mathrm{m}^{2}$. Thus, from block to block in Long and Beaton's experiments subjects would go from straining to see very dim stimuli to having their retinas blasted with enough light to produce longlasting afterimages. It is not especially surprising that subjects produced unstable data under these conditions.

Nevertheless, we would still feel properly chastened by Long's first criticism if we had, in fact, based our model on just our single "null-effect" study; but, in truth, the model we proposed was based on over a dozen studies conducted by several different investigators over a period of 25 years. The first stage of our model, a period of visible persistence beginning at stimulus onset and dependent upon stimulus energy, was based on studies conducted by Bowen et al. (1974), Cohene (1975), Di Lollo (1977, 1980), Efron (1970a, 1970b, 1970c), and Haber and Standing $(1969,1970)$. The second stage of our model, a period of informational persistence beginning at stimulus offset and relatively insensitive to stimulus energy, was based on studies conducted by Adelson and Jonides (1980), Di Lollo (1978), Eriksen and Rohrbaugh (1970), Scharf and Lefton (1970), and Sperling (1960), in addition to our own findings. All of these studies were cited in our original paper in support of our model; thus, Long's objection that our model was based on one null effect is simply incorrect.

What we find even more curious about Long's first criticism is that we acknowledged in our original paper the possibility that stimulus duration might have a small posi- 
tive effect on partial-report performance-but we also pointed out that our conclusions would be unchanged even if this were the case: "Regardless of whether increasing stimulus duration has no or only a slightly positive effect on partial report performance, its influence here is still vastly different from its influence on visible persistence, where an increase in stimulus duration causes a decrease in persistence duration" (Yeomans \& Irwin, 1985, pp. 166-167). That is, our distinction between visible and informational persistence rests on the differential effects that stimulus energy has on them, and not on a null effect per se. As the above quotation demonstrates, we made this point perfectly clearly in our original paper.

To summarize, Long's first criticism misses the mark because (1) our model was not based on one "noisy" study which found a null effect, and (2) our conclusions were dependent not on the null effect we found, but on the differential effects of stimulus duration and stimulus intensity on partial-report and visible persistence tasks that we and other investigators have found.

\section{The "Overlooked" Persistence}

Long's second criticism of our paper was that we overlooked numerous published results that are inconsistent with the two-stage model we proposed: "Specifically, several studies over the past two decades have provided clear evidence for a positive-energy persistence that outlasts target offset by several hundred milliseconds ... In the terminology originally suggested by Hawkins and Shulman (1979), Yeomans and Irwin's model omits the
Type II persistence phenomenon found in various persistence tasks"' (Long, 1985a, p. 382). As an alternative to our two-part model, Long proposes a three-part classification of persistence; Table 1 (reproduced from Long, 1985a) illustrates his three-part classification scheme. To summarize, Hawkins and Shulman defined Type I persistence tasks as those which measure visible persistence up to some distinct termination or offset; Long claims that this persistence is visible, exhibits inverse luminance or duration effects, and exhibits positive spatial frequency effects. Hawkins and Shulman defined Type II persistence tasks as those which measure a fading trace that is sometimes visible even after subjective persistence offset; according to Long, this persistence is visible, exhibits positive luminance or duration effects, and exhibits inverse spatial frequency effects. Finally, Long's conception of informational persistence is as a nonvisible, nonmaskable, spatiotopic, energy-independent representation.

There are several serious problems with Long's threepart classification scheme, problems whose exposition should make clear why we "overlooked" (actually, "rejected" is closer to the truth) the "Type II" studies championed by Long. We should note, first of all, that Long's use of "Type I" and "Type II"' is not consistent with that of Hawkins and Shulman. Hawkins and Shulman used these terms to refer to different procedures which had been used to examine a unitary persistence (or "sensory residual") after stimulus offset; Long uses the same terms to refer to different kinds of persistence, on the assumption that Type I and Type II procedures tap different un-

Table 1

Representative Sample of Visual Persistence/Iconic Memory Studies Categorized by Nature of Persistence Assessed and Type of Persistence Task Used

\begin{tabular}{|c|c|c|}
\hline Type I Persistence* & Type II Persistence $\dagger$ & Informational Persistence $\ddagger$ \\
\hline $\begin{array}{l}\text { Asynchrony-Judgment Task } \\
\text { Efron (1970c) } \\
\text { Bowen, Pola, \& Matin (1974) } \\
\text { Long \& Gildea (1981) } \\
\text { Long \& McCarthy (1982b) } \\
\text { Wilson (1983) } \\
\text { Moving Target Task } \\
\text { Allport (1968) } \\
\text { Smith (1969) } \\
\text { Dixon \& Hammond (1972) } \\
\text { Farrell (1984) } \\
\text { Flicker/Multiflash Task } \\
\text { Haber \& Standing (1969) } \\
\text { Hogben \& Di Lollo (1974) } \\
\text { Di Lollo (1977, 1980) } \\
\text { Di Lollo \& Wilson (1978) } \\
\text { Meyer \& Maguire (1977, 1981) } \\
\text { Bowling, Lovegrove, \& Mapperson (1979) } \\
\text { Bowling \& Lovegrove (1980, 1981) } \\
\text { Marx \& May (1983) } \\
\text { Long \& Sakitt (1981, 1984) } \\
\text { Lovegrove \& Meyer (1984) }\end{array}$ & $\begin{array}{l}\text { Probe-Matching Task } \\
\text { Sakitt (1976) } \\
\text { Sakitt \& Long (1979a) } \\
\text { Long \& Beaton (1980, 1981) } \\
\text { Long \& McCarthy (1982b) } \\
\text { Long (1984) } \\
\text { Long \& Sakitt (1984) } \\
\text { Long \& Wurst (1984) } \\
\text { Long (1985b) } \\
\text { Successive-Field Task } \\
\text { Eriksen \& Collins (1968) } \\
\text { Sakitt \& Long (1978, 1979b) } \\
\text { Long \& Sakitt (1980) } \\
\text { Kinnucan \& Friden (1981) } \\
\text { Long (1982) } \\
\text { Partial-Report Task } \\
\text { Keele \& Chase (1967) } \\
\text { Eriksen \& Rohrbaugh (1970) } \\
\text { Sakitt (1976) } \\
\text { Long \& Beaton (1982) } \\
\text { Long \& McCarthy (1982a) } \\
\text { Kling \& Long (1983) } \\
\end{array}$ & $\begin{array}{l}\text { Letter-Comparison Task } \\
\text { Posner \& Keele (1967) } \\
\text { Dot-Matrix Discrimination Task } \\
\text { Phillips (1974) } \\
\text { Repetition-Detection Task } \\
\text { Sperling \& Kaufman (1978) } \\
\text { Picture-Masking Task } \\
\text { Loftus, Johnson, \& Shimamura } \\
\text { (1985) }\end{array}$ \\
\hline
\end{tabular}


derlying processes. As Di Lollo (1983, 1984) has pointed out, there is little evidence to support this assumption. Perhaps as a result of this error, Long proceeds (in Table 1) to confuse the theoretical distinction between Type I and Type II persistence with a specific constellation of empirical results. That is, the studies categorized by Long in Table 1 as "Type I" or "Type II" are assigned on the basis of whether they show inverse or positive target energy effects, rather than on the theoretical basis of whether they measure subjective offset or a fading trace (Hawkins and Shulman's definition). As a result, Long's classification of specific experimental tasks in terms of the type of persistence they involve is meaningless. Di Lollo (1984), in a scholarly critique of the persistence literature, has convincingly shown that several of the studies listed by Long as "Type I" actually employed Type II persistence measures, as defined by Hawkins and Shulman; these include the studies by Allport (1968), Bowen et al. (1974), Dixon and Hammond (1972), Efron (1970c), Haber and Standing (1969), and Smith (1969). The study by Farrell (1984) can also be included in this list. These Type II studies, which Long has misclassified as "Type I" on the basis of their results, all show an inverse effect of target energy on persistence duration. This, of course, is completely inconsistent with Long's classification scheme.

Another serious problem with Long's classification scheme regards his treatment of Di Lollo's work (Di Lollo, 1977, 1980; Di Lollo \& Wilson, 1978; Hogben \& Di Lollo, 1974). Long categorizes these studies as Type I "multiple-flash" tasks, but categorizes the closely related work of Eriksen and Collins (1968) and Kinnucan and Friden (1981) as Type II "successive-field" tasks. The rationale Long gives for this distinction is that subjects in the Eriksen and Collins and Kinnucan and Friden experiments had to temporally integrate two flashes of information, whereas in the Di Lollo experiments subjects had to temporally integrate 24 dots sequentially presented in time. According to Long, the former case involves the simple integration of successive half-stimuli, which can make use of a gradually fading trace of the first flash, whereas in the latter case the plethora of successive stimulus offsets eliminates this source of persistence. In the former case, then, persistence will be positively related to stimulus energy, but in the latter case, it will be inversely related. The problem with this argument is that Di Lollo has shown, in the very articles that Long cites, an inverse relationship between stimulus duration and visible persistence duration even when the 24 dots are presented in 2 successive flashes, rather than 24 (Di Lollo, 1977, 1980; Hogben \& Di Lollo, 1974). Long has simply misrepresented Di Lollo's work. To reiterate, Di Lollo has shown quite convincingly, in what Long would classify as a Type II successive-field task, an inverse effect of stimulus energy on persistence duration; furthermore, several other investigators have also found similar negative effects of stimulus energy in this task (e.g., Cohene, 1975; Eriksen \& Collins, 1967; Pollack,
1973). In sum, over half the studies that Long has classified as "Type I" (on the basis of an inverse energy effect) should actually be classified as Type II (on the basis of Hawkins and Shulman's definition). Since these studies all show inverse energy effects, much of the force of Long's classification scheme is lost.

But what of the 20 studies that Long does include in the Type II column of Table 1? These studies presumably show a positive-energy visible persistence following stimulus offset, contrary to the predictions of the Yeomans and Irwin model. Of the 20 studies cited by Long to support his view, 16 were conducted by Long and/or Sakitt. So let us first consider the 4 studies conducted by others. Keele and Chase (1967) found increased overall performance in a partial-report task as stimulus intensity increased, with a small increase in persistence duration. But as previous investigators (e.g., Adelson \& Jonides, 1980; Bowling \& Lovegrove, 1982; Coltheart, 1980; Di Lollo, 1984) have pointed out, two of the three stimulus luminances employed by Keele and Chase were very high, intense enough to produce retinal afterimages. The use of such high stimulus intensities is not typical of most persistence studies; thus, the Keele and Chase study probably tells us little about general persistence phenomena. Furthermore, as Long pointed out in reference to Yeomans and Irwin (1985), the pattern of results obtained by Keele and Chase is rather equivocal; to paraphrase Long (1985a, p. 382), the improvement with increasing target energy could be due to improved target clarity rather than to increased persistence. Similar arguments apply to the 3 other studies that Long cites in support of a positiveenergy visible persistence; the studies by Eriksen and Collins (1968) and Eriksen and Rohrbaugh (1970) show improved performance with increases in target energy, but not increased persistence (cf. Bowling \& Lovegrove, 1982). In fact, Coltheart (1980) has argued against the existence of a positive-energy persistence from these same data. The study by Kinnucan and Friden (1981) involved a successive-field task in which the two half-stimuli varied in intensity, being either $\operatorname{dim}\left(8.9 \mathrm{~cd} / \mathrm{m}^{2}\right)$ or bright $\left(130.1 \mathrm{~cd} / \mathrm{m}^{2}\right)$. Kinnucan and Friden found that the first half-stimulus persisted longer when it was presented at the bright, as opposed to the dim, intensity. However, this intensity is also bright enough to produce retinal afterimages in the viewing conditions these investigators employed (Coltheart, 1980). So, as with the Keele and Chase study, this experiment tells us little about visible persistence per se. In sum, the four "nonpartisan" studies cited by Long to support the existence of a positive-energy visible persistence simply do nothing of the kind. We might also note at this point that there are several other "Type II" (partial report) studies, which Long did not cite, that show no positive effect of stimulus energy on performance (e.g., Adelson \& Jonides, 1980; Di Lollo, 1978; Scharf \& Lefton, 1970; Sperling, 1960).

Now let us consider the other 16 studies in the Type II column in Table 1, those conducted by Long and Sakitt and their collaborators. Nine of these studies (i.e., Kling 
\& Long, 1983; Long, 1982; Long \& Beaton, 1982; Long \& McCarthy, 1982a; Long \& Sakitt, 1980; Sakitt, 1976; Sakitt \& Long, 1978, 1979a, 1979b) can be rejected from further consideration because they employed dark-adapted subjects viewing high-luminance stimuli; thus, retinal afterimages, rather than visible persistence, probably determined task performance. No one denies that under the right conditions one can produce long-lasting persistence effects; as Adelson and Jonides (1980) put it, "a photographer's flashgun will do the trick nicely" (p. 492). Furthermore, it is well established that the duration of retinal afterimages increases with stimulus energy (e.g., Alpern \& Barr, 1962). But retinal afterimages probably tell us little about visible persistence, which routinely shows an inverse effect of stimulus energy on its duration. Since the Yeomans and Irwin (1985) model was not meant to be a model of afterimage formation, these studies are simply irrelevant. Another study (Long \& Sakitt, 1984) is also irrelevant to the present argument, because it did not investigate stimulus intensity or stimulus luminance, but rather spatial frequency effects on persistence duration.

Task performance in at least two other studies may not have been determined by visible persistence at all, but rather by other cognitive processes. Consider, for example, the task that subjects in the Long and Beaton (1980, 1981) experiments performed: Following the presentation of a variable-duration stimulus, subjects classified its duration as "short," "'medium," or "long." Although this judgment may (arguably) depend in part on visible persistence, other cognitive processes may also play a role (Allen, 1979; Thomas \& Weaver, 1975); finding that a long-duration stimulus is judged "longer" than a shortduration stimulus thus does not necessarily imply the existence of a positive-energy visible persistence, because the judgment might have been based on cognitive processing rather than on visible persistence.

Finally, let us consider the "probe-matching" task used by Long $(1984,1985 b)$, Long and McCarthy (1982b), and Long and Wurst (1984); according to Long's comment (1985a), the only difference between this task and the asynchrony-judgment task used by other investigators is in whether subjects respond to target offset (asynchronyjudgment, "Type I" persistence) or to the last fading trace of the stimulus (probe-matching, "Type Il" persistence). But, as we mentioned earlier, in at least two "asynchronyjudgment" tasks (Bowen et al., 1974; Efron, 1970c) subjects were instructed to respond to the fading trace of the stimulus rather than to its offset (Di Lollo, 1984). Thus, Long's distinction between these two types of tasks breaks down; it seems to us that the "asynchrony-judgment probe-matching"' task is simply an unreliable method, highly sensitive to shifts in an observor's criterion, that sometimes produces inverse effects and sometimes positive. In fact, this task has been criticized by several investigators, including Long (1980), on just these grounds (cf. Coltheart, 1980). If a task is known to produce ambiguous results, is there any reason to put much faith in it? We think not.
Let's summarize. Of the 20 studies that Long cites in support of the existence of a positive-energy visible persistence, 2 show improved performance, but not greater persistence, with increases in stimulus energy; 11 are irrelevant because they measured retinal afterimages rather than visible persistence; 1 is irrelevant because it didn't involve variations in stimulus energy; 2 are questionable because they don't obviously assess only visible persistence; and 4 are questionable because they use a procedure that is just as likely to produce inverse as positive effects of stimulus energy on persistence. Furthermore, Long has misclassified 10 Type II studies as "Type I," and all of these studies show inverse effects of stimulus energy on visible persistence duration. Finally, Long fails to cite 7 Type II studies which also show either no or an inverse effect of stimulus energy on visible persistence duration. Our conclusion from this accounting is that there is no compelling evidence for the existence of a positiveenergy visible persistence. That's why we didn't include it in our model.

\section{Conclusions}

In conclusion, we believe that Long's objections to our paper are without merit, and that his three-part classification of persistence is seriously flawed. In particular, his distinction between "Type I" and "Type II" persistence is hopelessly confused, because it is defined in contradictory theoretical and empirical terms. We would like to echo Di Lollo's (1984) recent call for a moratorium in the use of these terms, since they seem to serve no useful purpose. We suggest that Long might use, instead, the terms "visible persistence" and "retinal afterimages" to denote the visual processes underlying the differences in performance that he observes.

Our two-stage model (Yeomans \& Irwin, 1985), which distinguishes between visible persistence (i.e., the phenomenal trace of a stimulus) and informational persistence (i.e., knowledge about the visual properties of a stimulus), accounts well for the relevant experimental literature. Although we have had little to say about the third category in Long's classification scheme, that of informational persistence, we might add that we have recently extended the model described in Yeomans and Irwin (1985) on the basis of several experiments designed to further elucidate the characteristics of informational persistence (Irwin \& Yeomans, in press). Specifically, this research contrasted two alternative conceptions of informational persistence: One conception was that informational persistence consists of a visual memory that begins at stimulus offset and lasts for $150-300 \mathrm{msec}$, independently of exposure duration; the second conception was that informational persistence arises from a nonvisual memory that contains spatial coordinates for displayed items along with abstract identity codes for those items. Three experiments were conducted in which $3 \times 3$ letter arrays were presented for durations ranging from 50 to 500 msec. A mask presented at one of the letter locations at varying intervals after array offset cued report of an 
entire row of the array. Comparison of the cued row's masked and unmasked letters revealed that spatially specific visual (i.e., maskable) information persisted for $150-300 \mathrm{msec}$ after stimulus offset, regardless of exposure duration, supporting the visual conception of informational persistence. But there was also support for the nonvisual conception: Accuracy for both masked and unmasked letters increased as exposure duration increased, and the number of item intrusion errors decreased, suggesting that some translation of the stimulus array into durable identity codes took place during the exposure period. Based on these results, we proposed that informational persistence consists of a visual analog representation that maintains form and location information about the contents of a display for $150-300 \mathrm{msec}$ after stimulus offset, regardless of exposure duration, and to a nonvisual identity representation which also contains some relatively poor coding of spatial layout. This new model is simply an expansion of the two-stage model proposed by Yeomans and Irwin (1985).

\section{REFERENCES}

Adelson, E. H., \& Jonides, J. (1980). The psychophysics of iconic storage. Journal of Experimental Psychology: Human Perception \& Performance, 6, 486-493.

Allan, L. G. (1979). The perception of time. Perception \& Psychophysics, 26, 340-354.

AllPORT, D. A. (1968). Phenomenal simultaneity and the perceptual moment hypothesis. British Journal of Psychology, 59, 395-406.

ALPERN, M., \& BARR, L. (1962). Durations of the afterimages of brief light flashes and the theory of the Broca and Sulzer phenomenon. Journal of the Optical Society of America, 52, 219-221.

Bowen, R. W., PolA, J., \& MAtin, L. (1974). Visual persistence: Effects of flash luminance, duration, and energy. Vision Research, 14, 295-303.

Bowling, A., \& Lovegrove, W. (1980). The effect of stimulus duration on the persistence of gratings. Perception \& Psychophysics, 27, 574-578.

Bowling, A., \& Lovegrove, W. (1981). Two components to visible persistence: Effects of orientation and contrast. Vision Research, 21, 1241-1251.

Bowling, A., \& Lovegrove, W. (1982). Iconic memory: Fallacies persist (?). Perception \& Psychophysics, 31, 194-198.

Bowling, A., Lovegrove, W., \& Mapperson, B. (1979). The effect of spatial frequency and contrast on visual persistence. Perception, $8,529-539$.

Conene, L. S. (1975). Iconic memory of dot patterns: Preliminary report. Perceptual \& Motor Skills, 41, 167-170.

Coltheart, M. (1980). Iconic memory and visible persistence. Perception \& Psychophysics, 27, 183-228.

Di Lollo, V. (1977). Temporal characteristics of iconic memory. $\mathrm{Na}$ ture, 267, 241-243.

Di LoLLO, V. (1978). On the spatio-temporal interactions of brief visual displays. In R. H. Day \& G. V. Stanley (Eds.), Studies in perception (pp. 39-55). Perth: University of Western Australia Press.

Di Lollo, V. (1980). Temporal integration in visual memory. Journal of Experimental Psychology: General, 109, 75-97.

Di LoLLo, V. (1983). On laterality of visual aftereffects: A rejoinder. Perception \& Psychophysics, 33, 599-603.

DI LOLLO, V. (1984). On the relationship between stimulus intensity and duration of visible persistence. Journal of Experimental Psychology: Human Perception \& Performance, 10, 144-151.

Di Lollo, V., \& Wilson, A. E. (1978). Iconic persistence and perceptual moment as determinants of temporal integration in vision. $\mathrm{Vi}$ sion Research, 18, 1607-1610.
Dixon, N. F., \& Hammond, J. (1972). The attenuation of visual persistence. British Journal of Psychology, 63, 243-254.

EFron, R. (1970a). Effect of stimulus duration on perceptual onset and offset latencies. Perception \& Psychophysics, 8, 231-234.

Efron, R. (1970b). The minimum duration of a perception. Neuropsychologia, 8, 57-63.

EFron, R. (1970c). The relationship between the duration of a stimulus and the duration of a perception. Neuropsychologia, 8, 37-55.

ERIKSEN, C. W., \& Collins, J. F. (1967). Some temporal characteristics of visual pattern perception. Journal of Experimental Psychology, 74, 476-484.

ERIKSEN, C. W., \& Collins, J. F. (1968). Sensory traces versus the psychological moment in the temporal organization of form. Journal of Experimental Psychology, 77, 376-382.

ERIKSEN, C. W., \& RohrbauGH, J. W. (1970). Visual masking in multielement displays. Journal of Experimental Psychology, 83, 147-154.

FARRELL, J. E. (1984). Visible persistence of moving objects. Journal of Experimental Psychology: Human Perception \& Performance, 10, $502-511$.

HABER, R. N., \& STANDING, L. (1969). Direct measures of short-term visual storage. Quarterly Journal of Experimental Psychology, 21, 43-54.

Haber, R. N., \& Standing, L. (1970). Direct estimates of the apparent duration of a flash. Canadian Journal of Psychology, 24, 216-229.

Hawkins, H. L., \& Shulman, G. L. (1979). Two definitions of persistence in visual perception. Perception \& Psychophysics, 25, 348-350.

Hogben, J. H., \& Di Lollo, V. (1974). Perceptual integration and perceptual segregation of brief visual stimuli. Vision Research, 14, 1059-1069.

Irwin, D. E., \& Yeomans, J. M. (in press). Sensory registration and informational persistence. Journal of Experimental Psychology: $\mathrm{Hu}$ man Perception \& Performance.

Keele, S. W., \& Chase, W. G. (1967). Short-term visual storage. Perception \& Psychophysics, 2, 383-386.

KinnuCan, M. T., \& Friden, T. P. (1981). Visual form integration and discontinuity detection. Journal of Experimental Psychology: Human Perception \& Performance, 7, 948-953.

KLING, S. C., \& LoNG, G. M. (1983). The effects of target size and retinal location on a partial report task of iconic memory. Bulletin of the Psychonomic Society, 21, 435-438.

Loftus, G. R., Johnson, C. A., \& Shimamura, A. P. (1985). How much is an icon worth? Joumal of Experimental Psychology: Human Perception \& Performance, 11, 1-13.

LoNG, G. M. (1980). Iconic memory: A review and critique of the study of short-term visual storage. Psychological Bulletin, 88, 785-820.

LoNG, G. M. (1982). Receptor interactions and visual persistence. $\mathrm{Vi}$ sion Research, 22, 1285-1292.

LoNG, G. M. (1984). The pretreatment weighting technique. Journal of Experimental Psychology: Human Perception \& Performance, 10, 40-43.

LoNG, G. M. (1985a). The varieties of visual persistence: Comments on Yeomans and Irwin. Perception \& Psychophysics, 38, 381-385.

LONG, G. M. (1985b). Visual persistence from brief letters and pictures. Vision Research, 25, 887-892.

LONG, G. M., \& BEATON, R. J. (1980). The contribution of visual persistence to the perceived duration of brief targets. Perception \& Psychophysics, 28, 422-430.

LoNG, G. M., \& Beaton, R. J. (1981). The effects of stimulus numerosity, retinal location, and rod contrast on perceived duration of brief visual stimuli. Perception \& Psychophysics, 29, 389-394.

LONG, G. M., \& BEATON, R. J. (1982). The case for peripheral persistence: Effects of target and background luminance on a partial-report task. Joumal of Experimental Psychology: Human Perception \& Performance, 8, 383-391.

LONG, G. M., \& GILDEA, T. J. (1981). Latency for the perceived offset of brief target gratings. Vision Research, 21, 1395-1399.

LONG, G. M., \& MCCARTHY, P. R. (1982a). Rod persistence on a partialreport task with scotopic and photopic backgrounds. American Journal of Psychology, 95, 302-322.

Long, G. M., \& MCCARTHY, P. R. (1982b). Target energy effects on 
Type 1 and Type 2 visual persistence. Bulletin of the Psychonomic Society, 19, 219-221.

LONG, G. M. \& SAKITT, B. (1980). The retinal basis of iconic memory: Eriksen and Collins revisited. American Journal of Psychology, 93. 195-207.

LoNG, G. M., \& SAKITT, B. (1981). Differences between flicker and nonflicker persistence tasks: The effects of luminance and the number of cycles in a grating target. Vision Research, 21, 1387-1393.

LoNG, G. M. , \& SAKITT, B. (1984). Visual persistence from flickered and flashed gratings: Methodological considerations. Bulletin of the Psychonomic Society, 22, 1-4.

LONG, G. M., \&URST, S. A. (1984). Complexity effects on reactiontime measures of visual persistence: Evidence for peripheral and central contributions. American Journal of Psychology, 97, 537-561.

LOVEgRove, W. J., \& MEYER, G. E. (1984). Visible persistence as a function of spatial frequency, number of cycles and retinal area. $V i$ sion Research, 24, 255-260.

MARX, M. S., \& MAY, J. G. (1983). The relationship between temporal integration and persistence. Vision Research, 23, 1101-1106.

MEYER, G. E., \& MAGUIRE, W. M. (1977). Spatial frequency and the mediation of short-term visual storage. Science, 198, 524-525.

MEYER, G. E., \& MAGUiRE, W. M. (1981). Effects of spatial-frequency specific adaptation and target duration on visual persistence. Journal of Experimental Psychology: Human Perception \& Performance, 7, 151-156.

Phillips, W. A. (1974). On the distinction between sensory storage and short-term visual memory. Perception \& Psychophysics, 16, 283-290.

Pollack, I. (1973). Interaction effects in successive visual displays: An extension of the Eriksen-Collins paradigm. Perception \& Psychophysics, 13, 367-373.
Posner, M. I., \& KeElE, S. W. (1967). Decay of visual information from a single letter. Science, 158, 137-139.

SAKITt, B. (1976). Iconic memory. Psychological Review, 83, 257-276.

SakitT, B., \& LoNG, G. M. (1978). Relative rod and cone contributions in iconic storage. Perception \& Psychophysics, 23, 527-536.

SAKITT, B., LONG, G. M. (1979a). Cones determine subjective offset of a stimulus but rods determine total persistence. Vision Research, 19, 1439-1441.

SAKITT, B. \& LoNG, G. M. (1979b). Spare the rod and spoil the icon. Journal of Experimental Psychology: Human Perception \& Performance, 5, 19-30.

SCHARF, B., \& LeFTON, L. A. (1970). Backward and forward masking as a function of stimulus and task parameters. Journal of Experimental Psychology, 84, 331-338.

Sмiтн, V. C. (1969). Scotopic and photopic functions for visual band movement. Vision Research, 9, 293-304.

SPERLING, G. (1960). The information available in brief visual presentations. Psychological Monographs, 74(11, Whole No. 498).

SPerling, G., \& Kaufman, J. (1978, August). Three kinds of visual short-term memory. Paper presented at the Eighth International Symposium on Attention and Performance, Princeton, NJ.

Thomas, E. A. C., \& Weaver, W. B. (1975). Cognitive processing and time perception. Perception \& Psychophysics, 17, 363-367.

WILSON, J. T. L. (1983). Effects of stimulus luminance and duration on responses to onset and offset. Vision Research, 23, 1699-1709.

Yeomans, J. M., \& IRWIN, D. E. (1985). Stimulus duration and partial report performance. Perception \& Psychophysics, 37, 163-169.

(Received March 5, 1986; accepted for publication March 15, 1986.) 